\title{
In-Situ Synthesis of Methyl Cellulose Film Decorated with Silver Nanoparticles as a Flexible Surface-Enhanced Raman Substrate for the Rapid Detection of Pesticide Residues in Fruits and Vegetables
}

\author{
Qijia Zhang ${ }^{1}$, Guangda $X u^{1}{ }^{1}, N_{a}$ Guo ${ }^{1}$, Tongtong Wang ${ }^{1}$, Peng Song ${ }^{2, *(D)}$ and Lixin Xia ${ }^{1, *}$ \\ 1 College of Chemistry, Liaoning University, Shenyang 110036, China; zqj13940305120@163.com (Q.Z.); \\ xuguangdalnu@163.com (G.X.); 18404713138@163.com (N.G.); 18340312652@163.com (T.W.) \\ 2 Yingkou Institute of Technology, Yingkou 115014, China \\ * Correspondence: songpeng@lnu.edu.cn (P.S.); lixinxia@lnu.edu.cn (L.X.); Tel.: +86-24-6220-2258 (L.X.)
}

Citation: Zhang, Q.; Xu, G.; Guo, N.; Wang, T.; Song, P.; Xia, L. In-Situ Synthesis of Methyl Cellulose Film Decorated with Silver Nanoparticles as a Flexible Surface-Enhanced Raman Substrate for the Rapid Detection of Pesticide Residues in Fruits and Vegetables. Materials 2021, 14, 5750. https://doi.org/10.3390/ ma14195750

Academic Editors: Piotr Piszczek and Aleksandra Radtke

Received: 29 August 2021

Accepted: 24 September 2021

Published: 1 October 2021

Publisher's Note: MDPI stays neutral with regard to jurisdictional claims in published maps and institutional affiliations.

Copyright: (c) 2021 by the authors. Licensee MDPI, Basel, Switzerland. This article is an open access article distributed under the terms and conditions of the Creative Commons Attribution (CC BY) license (https:/ / creativecommons.org/licenses/by/ $4.0 /)$.

\begin{abstract}
The purpose of this study was to develop a flexible substrate methylcellulose-decorated silver nanoparticles (MC/Ag NPs) film and explore its application in fruits and vegetables by surface enhanced Raman spectroscopy (SERS) technology for rapid detection of pesticides. The performance of the MC/ Ag NPs film substrate was characterized by Nile blue A (NBA), and the detection limit was as low as $10^{-8} \mathrm{M}$. The substrate also exhibited satisfactory Raman signal strength after two months of storage. The impressive sensitivity and stability were due to the excellent homogeneity of the silver nanoparticles that were grown in situ in the methylcellulose matrix, which generated "hot spots" between the silver nanoparticles without a large amount of aggregation, and resulted in the ultra-high sensitivity and excellent stability of the MC/Ag NPs film substrate. The MC/Ag NPs film substrate was used to detect thiram pesticides on tomato and cucumber peels, and the minimum detectable level of thiram was $2.4 \mathrm{ng} / \mathrm{cm}^{2}$, which was much lower than the maximum residue level. These results indicate that the MC/Ag NPs film is sensitive to rapid detection of multiple pesticides in food.
\end{abstract}

Keywords: surface enhanced Raman scattering; flexible; thiram; MC / Ag NPs film; in situ

\section{Introduction}

Pesticide residues in foods have attracted much attention in recent years as consuming fruits and vegetables that are contaminated with pesticides can cause potential health problems, such as poisoning [1]. Therefore, there is strong demand for the detection of pesticide residues in agricultural products. Common methods of analyzing pesticide residues include high performance liquid chromatography (HPLC) [2] and gas chromatography (GC) combined with different detection techniques [3]. Such methods are sensitive, standardized, and are common, and are regarded as the gold standard [4] for pesticide detection. However, these analytical methods also have some drawbacks, such as complex pre-processing steps, time-consuming analytical processes, professional technicians, and the need for large and expensive instrumentation. In recent years, surface enhanced Raman spectroscopy (SERS) has been regarded as a promising method for rapid and nondestructive sample detection. SERS technology has the ability to accurately identify the signal fingerprints of analytes, and it can be applied to multiple fields.

Since its discovery in the 1970s, surface enhanced Raman scattering (SERS) has attracted increasing interest as a powerful analytical tool that can provide vibrational spectral information for the identification and quantification of multiple analyses $[5,6]$. With the great development of laser technologies and nanotechnologies, the application of SERS has been extended to multiple fields, including agricultural [7-10], environmental [11], medical [12], and biological [13,14], and it has also been used for art protection [15]. To 
better apply SERS to such fields, an important requirement was to develop reasonably designed ultra-sensitive, highly stable and replicable SERS substrates that could generate strong local electromagnetic fields (EM) in the gap of plasma nanostructure, that is, SERS "hot spots" [16-19]. Traditional SERS substrate was usually composed of noble metals, such as silver, gold, or copper, which can be prepared as colloidal nanoparticles or rigid materials as substrates. Colloidal nanoparticles are generally cheap to prepare and easy to modify. Many functional chemicals have been used to modify such nanoparticles [20], but colloidal systems have serious aggregation problems. In addition, The SERS spectra collected from the aggregated colloidal system were determined by the experimental conditions [21]. In contrast, rigid substrates ensure that these colloidal structures have excellent uniformity and reproducibility. However, due to the difficulty in collecting surface analysis of irregular samples on rigid substrates, SERS detection often required complex sample pretreatment steps [22]. In addition, the application of rigid substrates was limited by their high costs and complicated manufacturing process. Therefore, it is still necessary to develop a multifunctional SERS substrate that is suitable for routine analysis.

To overcome the above challenges, scientists have recently studied a variety of flexible materials, such as polydimethylsiloxane (PDMS) [23], polymethyl methacrylate (PMMA) [24], chitosan [25], tape [26], and bacterial nanocellulose [27], among others, as the carrier materials for decorative precious metal nanoparticles. For example, Kumar et al. first prepared oriented silver nanorods using the swept angle deposition technique and the thermal evaporation of silver powder on a silicon substrate, after which they used a PDMS film [28] to strip the arrays from silicon wafers. Chen et al. constructed SERS tapes using the drop deposition method to decorate commercial tapes with Au NPs [26]. The constructed SERS tape could directly extract thiram pesticide from foods for SERS detection. In addition, a simple method for the in situ synthesis of various nanostructures on cellulose paper has also been reported [29]. Although these flexible substrates have many advantages in actual sample detection compared to traditional rigid substrates, they also have disadvantages such as the necessity for cumbersome manufacturing processes, inhomogeneous distribution of "hot spots", and unstable SERS signals, which can limit their actual or on-site detection. As silver nanostructures stored in the air environment for a long time are easily oxidized, SERS enhancement effect will inevitably decrease during this process. Many methods have been evaluated for maintaining SERS performance of substrates, including coating the nanostructure, storing at low temperatures, or protecting with inert gases. Methyl cellulose is rich in hydroxyl and can be used as a carrier for the growth of nanoparticles. Moreover, it is easy to obtain, non-toxic, water-soluble, and cheap. Methylcellulose is a typical non-ionic polymer, which can stabilize ion concentration extremely well [30].

In this study, we developed a simple strategy to maintain the SERS activity of a substrate using the in situ growth of silver nanoparticles in a methylcellulose matrix as a film (MC/Ag NPs film). The matrix can protect the silver nanoparticles from the external environment. The substrate can not only be directly immersed in Nile blue A (NBA) solution for Raman detection, but can also be wiped on the surface of fruits and vegetables to detect pesticide residues. The MC/Ag NPs film substrate exhibited high detection sensitivity in the NBA solution at concentrations as low as $10^{-8} \mathrm{M}$. The MC/ Ag NPs film substrate also exhibited high sensitivity for the detection of thiram pesticides. More importantly, the MC/Ag NPs film SERS can realize the complete extraction and detection process without any other conditions. Thus, the proposed flexible MC/Ag NPs film SERS substrate can be broadly applied in the field for food safety analyses.

\section{Materials and Methods}

\subsection{Materials}

Methyl cellulose (MC), Nile Blue A (NBA), and thiram pesticides were purchased from Aladdin Industrial Co. (Shanghai, China). Silver nitrate $\left(\mathrm{AgNO}_{3}\right)$ was obtained from Sinopharm Chemical Reagent Co., Ltd. (Shanghai, China). Foods such as tomatoes 
and cucumbers were bought from a local supermarket in Shenyang, China. All aqueous solutions used in the study were freshly prepared in Milli-Q water $\left(>18 \mathrm{M} \Omega \cdot \mathrm{cm}^{-1}\right)$.

\subsection{Characterizations}

Scanning electron microscopic characterization was performed using a JEOL JSM7400F Scanning electron microscope (SEM) at an operating voltage of $5 \mathrm{kV}$ (Hitachi, Tokyo, Japan). Scanning electron microscope X-ray energy dispersive microanalysis (SEM-EDX) was performed using a Gemini 500 instrument (Zeiss, Oberkochen, Germany). X-ray diffraction (XRD) patterns were recorded on a Bruker D8 ADVANCE diffractometer by employing CuKa radiation. SERS signal was measured on Renishaw by Via-Reflex microRaman spectrometer with a $532 \mathrm{~nm}$ laser. The sample was exposed for $10 \mathrm{~s}$ at $1 \%$ laser $(0.5 \mathrm{~mW})$ and was scanned five times. At least 36 spots on the same SERS substrate were detected, and all collected spectra were averaged for the analysis.

\subsection{In Situ Growth of Nanoparticles}

A total of $100 \mathrm{~mL}$ of water was heated to about $70{ }^{\circ} \mathrm{C}$, and $1.0 \mathrm{~g}$ of methyl cellulose powder was added with slow stirring. A slurry gradually formed and a uniform suspension was obtained. The suspension was then cooled to obtain a clear and transparent solution. Freshly prepared $0.01 \mathrm{M} \mathrm{AgNO}_{3}$ solution was added to the methyl cellulose solution and stirred at $20^{\circ} \mathrm{C}$ for $24 \mathrm{~h}$.

\subsection{Fabrication of the Thin Film SERS Substrate}

The methylcellulose solution grown in situ with $\mathrm{AgNO}_{3}$ was poured into the mold to make a solid film. A volume of $15 \mathrm{~mL}$ methyl cellulose solution was poured into a petri dish with a diameter of $60 \mathrm{~mm}$ and dried at $60{ }^{\circ} \mathrm{C}$ for $16 \mathrm{~h}$.

\subsection{Detection of NBA Solutions}

To test the performance of the film SERS substrates, NBA was selected as the Raman model probe. Briefly, NBA of different concentrations $\left(10^{-4} \mathrm{M}, 10^{-5} \mathrm{M}, 10^{-6} \mathrm{M}, 10^{-7} \mathrm{M}\right.$, $10^{-8} \mathrm{M}$ ) were prepared and the film substrate was immersed in the solution for $30 \mathrm{~min}$. The film was then dried at room temperature until Raman detection.

\subsection{Detection of Pesticide Residues}

The foods (tomatoes and cucumbers) were washed with ultrapure water. To simulate SERS analysis of real samples, fruits and vegetables were peeled and the peels were cut into $1 \times 1 \mathrm{~cm}^{2}$ squares. Then, $10 \mu \mathrm{L}$ of the as-prepared pesticide solution was spread onto each peel square and dried. The SERS film was then wiped onto each sample and pressed. The substrate was held at a certain pressure for $10 \mathrm{~s}$, before being peeled off slowly and carefully. The SERS film substrate was then moved to the glass slide for further SERS analysis.

\section{Results and Discussion}

\subsection{Fabrication and Morphological Characterization of the MC/Ag NPS SERS Film}

A stable and high-performing SERS film substrate was achieved by decorating Ag NPs in an MC matrix. Scheme 1 shows the schematic diagram of preparation and detection of the SERS film substrate. The flexible film substrate showed a good ability to adapt to different shapes. It can not only be directly immersed in the analysis solution, but also be wiped on the surface of real samples to detect pesticides.

The methylcellulose solution containing silver nitrate was poured into a petri dish and dried at $60^{\circ} \mathrm{C}$. After $16 \mathrm{~h}$, a reddish-brown solid film was formed, which can be seen in Figure 1A. We characterized the morphology of the film by SEM, and the results are shown in Figure 1B. The fibrous structure of the cellulose and the successful growth of the Ag NPs could be clearly seen in the methylcellulose matrix. The "hot spots" of the SERS substrate were greatly enhanced, and the Raman signal was significantly improved. As shown in Figure 1C, elemental mapping was done with SEM-EDX. From the three 
element distribution diagrams in Figure 1C, we can also see that the Ag NPs are evenly distributed inside the film and on its surface, which provides favorable conditions for the good sensitivity and uniformity of the substrate. It is well known that methyl cellulose has a certain degree of water solubility, but this will cause inconvenience to actual detection on site. We have characterized the hydrophilic and hydrophobic properties of methyl cellulose, and the contact angle of water droplets was $116.7^{\circ}$ as shown in Figure S1, which proves the hydrophobic properties of the surface of the MC/Ag NPs film.

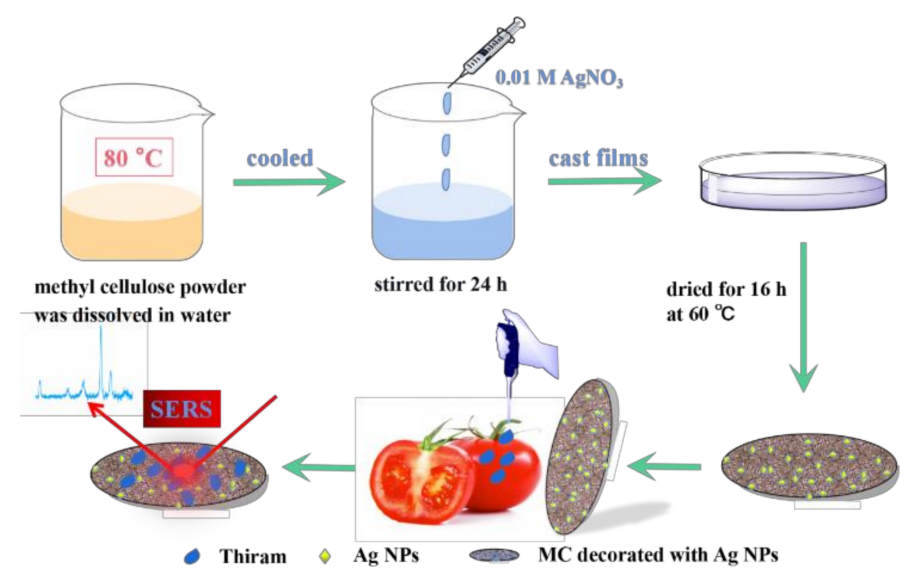

Scheme 1. Schematic illustration of the MC/Ag NPs SERS film fabrication and SERS measurement steps.

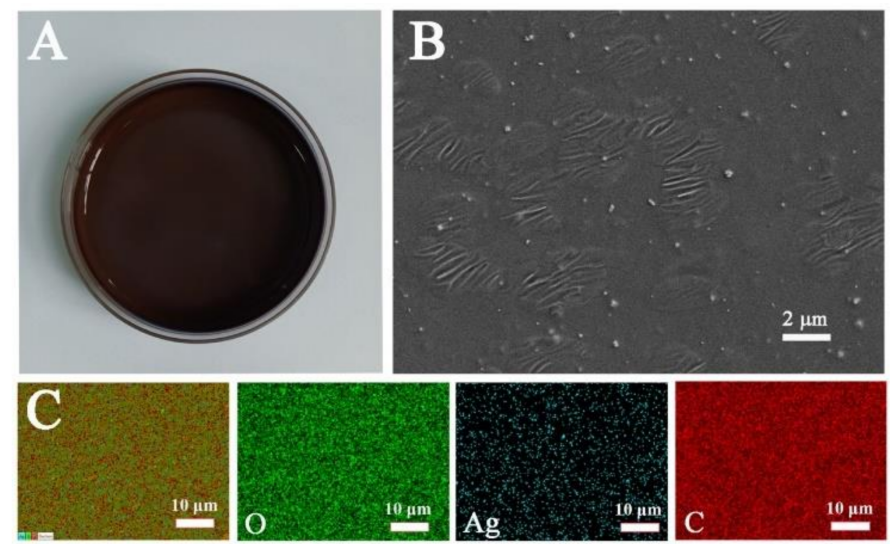

Figure 1. MC decorated with Ag NPs before drying (A), SEM image of the MC/Ag NPs SERS film substrate (B), and SEM-EDX images of the MC/Ag NPs film substrate (C).

The XRD patterns of methylcellulose and methylcellulose decorated with silver nanoparticles are shown in Figure 2. The two samples showed the same diffraction peaks around $2 \theta$ at $20.9^{\circ}, 31.9^{\circ}$, and $45.5^{\circ}$, which was the result of the low levels of crystalline methylcellulose. In addition, from the MC/Ag NPs film, four distinct peaks were observed at 38.2, and 77.5, which are attributed to the (1 111$)$, and (3 11 1) planes, of the face-centered cubic silver crystals. The presence and contents of elements in the MC/Ag NPs film in Figure S2 were also shown using energy dispersion spectroscopy (EDS). 


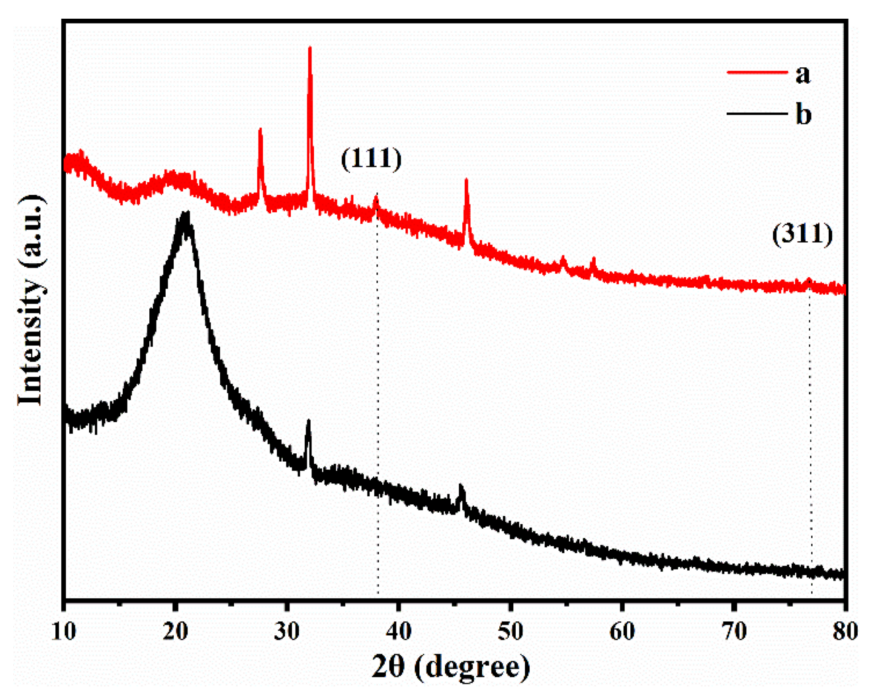

Figure 2. XRD spectra of the MC/Ag NPs film (a) and pure MC (b).

\subsection{Performance of the MC/Ag NPs Film}

Sensitivity and uniformity are the main factors affecting any SERS substrate. Therefore, to evaluate the SERS performance, the MC/Ag NPs film substrate was used to detect NBA at different concentrations (Figure 3A). The Raman band at $590 \mathrm{~cm}^{-1}$ (the characteristic peak of NBA) was used for the quantitative assessment of SERS sensitivity. Even when NBA concentration was reduced to $10 \mathrm{nM}$, the SERS spectral characteristic peak of $590 \mathrm{~cm}^{-1}$ could still be recognized. We can also see from the figure that the NBA has a wide linear detection range, about $10^{-4}$ to $10^{-8} \mathrm{M}$. To further evaluate the SERS performance of our $\mathrm{MC} / \mathrm{Ag}$ NPs film substrate, we calculated the enhancement factor (EF) [31] as follows.

$$
\mathrm{EF}=\left(\mathrm{I}_{\mathrm{SERS}} / \mathrm{N}_{\mathrm{SERS}}\right) /\left(\mathrm{I}_{\mathrm{NR}} / \mathrm{N}_{\mathrm{NR}}\right)
$$

In Equation (1), $\mathrm{I}_{\mathrm{SERS}}$ is the integrated intensities of SERS, and $\mathrm{I}_{\mathrm{NR}}$ is the normal Raman scattering spectra of NBA. $\mathrm{N}_{\text {SERS }}$ is the number of molecules in the laser excitation region on the MC/Ag NPs film. $\mathrm{N}_{\text {SERS }}$ and $\mathrm{N}_{\mathrm{NR}}$ were derived from calculations mentioned in a previous study [32]. Therefore, The MC/Ag NPs film calculated from Equation (1) was $1.7 \times 10^{5}$.
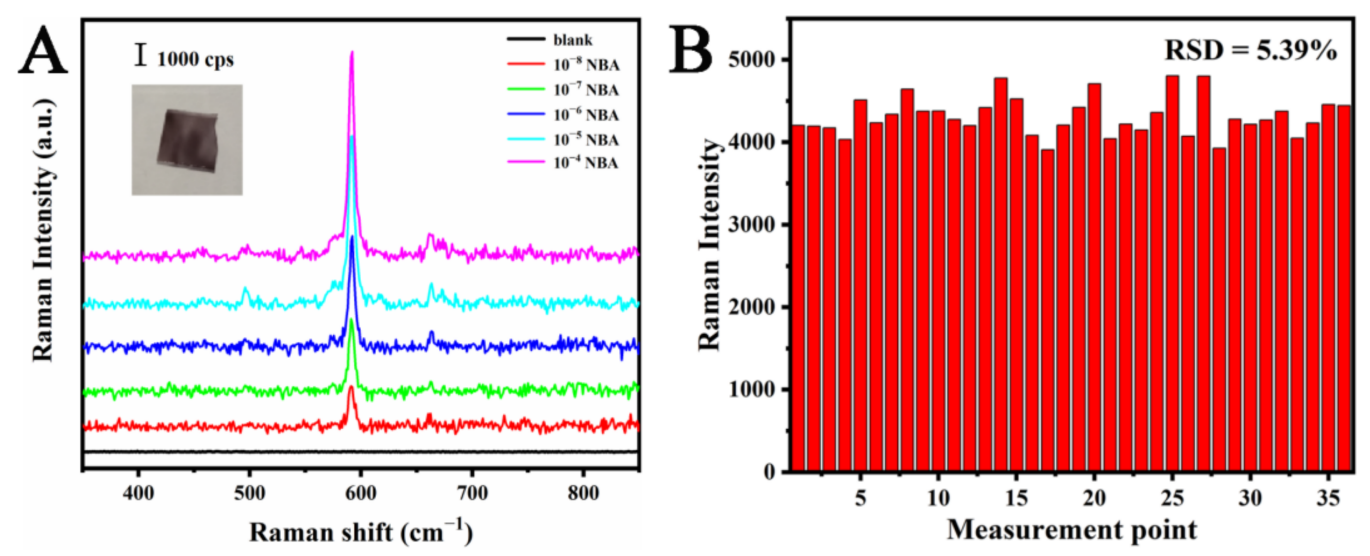

Figure 3. (A) SERS spectra of aqueous solutions containing different concentrations of NBA. (B) SERS intensity of NBA at $590 \mathrm{~cm}^{-1}$ from 36 random detection points on the same MC $/ \mathrm{Ag}$ NPs film.

To further study the uniformity of the MC/Ag NPs film substrate, we separately studied the uniformity on the same substrate and the uniformity between different substrates. Thirty-six detection points were randomly selected for Raman analyses, and NBA was used as the Raman marker. The Raman intensities at $590 \mathrm{~cm}^{-1}$ was used as the standard 
to draw the bar graph in Figure 3B, and the relative standard deviation (RSD) was 5.39\%. In order to evaluate the substrate-to-substrate uniformity, the SERS spectra of 40 points randomly selected from eight different substrates were measured (Figure $4 \mathrm{~A}$ ). In addition, we used the Raman intensities at $590 \mathrm{~cm}^{-1}$ as the standard to draw the bar graph in Figure 4B, and the RSD was $7.47 \%$. It was generally believed that the point-to-point or substrate-to-substrate RSD of substrates for quantitative analyses should be less than $20 \%[33,34]$. Therefore, the results show that the MC/Ag NPs film exhibited acceptable reproducibility and could be used as a reliable SERS substrate for quantitative analysis.
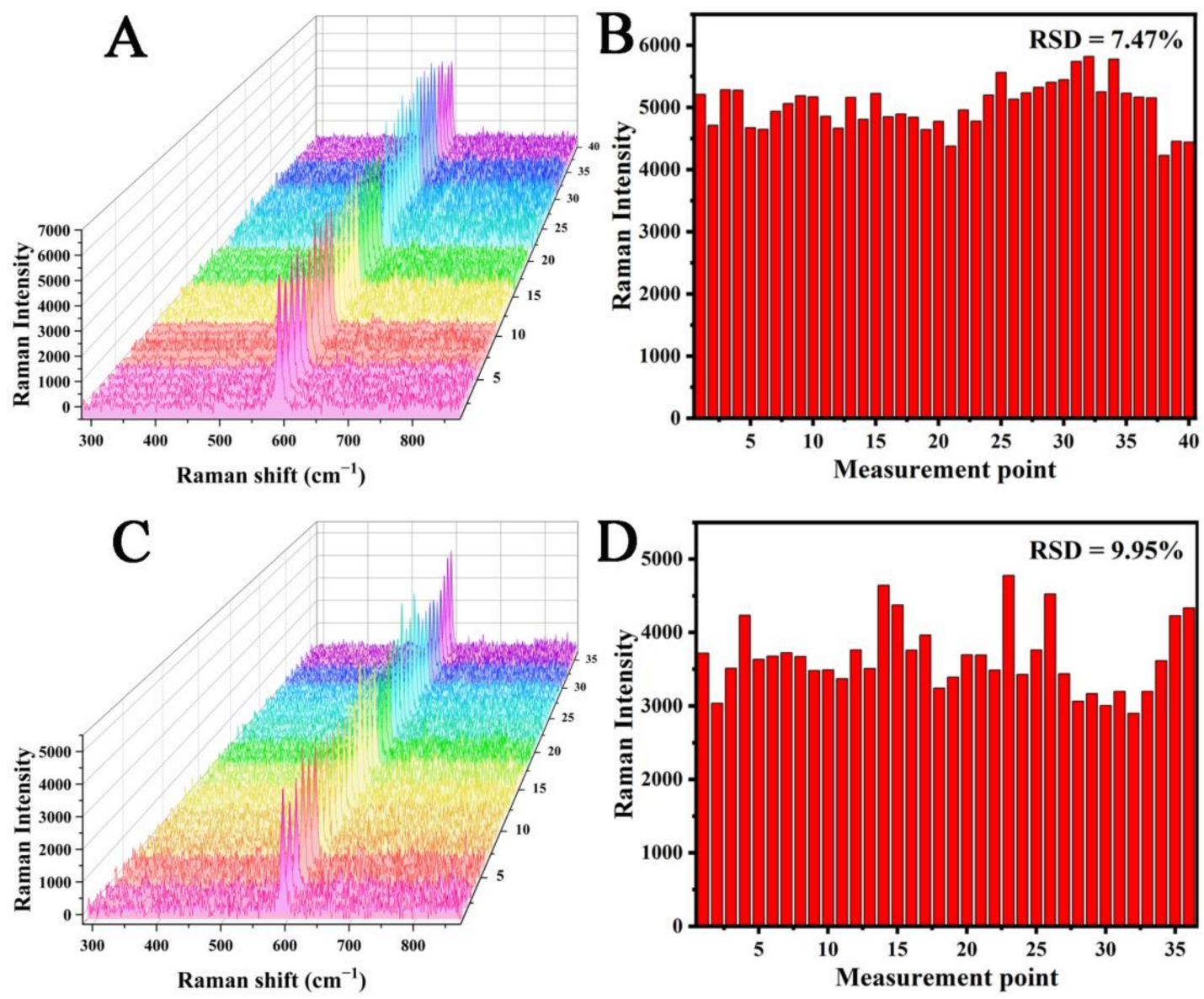

Figure 4. (A) SERS spectra of a $10^{-6} \mathrm{M}$ NBA solution acquired at 40 spots on the MC/Ag NPs film. (B) SERS intensity of NBA at $590 \mathrm{~cm}^{-1}$ from 40 random points. (C) SERS spectra of a $10^{-6} \mathrm{M}$ NBA solution acquired at 36 spots on the $\mathrm{MC} / \mathrm{Ag}$ NPs film after incubation for two months at room temperature. (D) SERS intensity of NBA at $590 \mathrm{~cm}^{-1}$ from 36 random points.

Stability is the key to the practical application of MC/Ag NPs film substrates [28]. However, Ag NPs will gradually be oxidized at room temperature, resulting in the reproducibility of the SERS signal of the substrate gradually decreasing. Thus, to assess the stability of the substrate, the MC/Ag NPs film was stored at room temperature for two months, after which it was immersed in freshly prepared $10^{-6} \mathrm{M} \mathrm{NBA}$ (Figure 4C). The Raman intensity of NBA at $590 \mathrm{~cm}^{-1}$ did not decrease significantly, and the RSD was $9.95 \%$ (Figure 4D). Thus, those results indicated that the MC/Ag NPs film had good stability at room temperature.

\subsection{Detection of Thiram on MC/Ag NPs Films}

Figure 5A shows the MC/Ag NPs film as the SERS substrate and the SERS spectrum of the thiram solution with the concentration increased from $0.024 \mathrm{mg} / \mathrm{L}$ to $240 \mathrm{mg} / \mathrm{L}$. The Raman characteristic peaks at 1146, 1380, and $1505 \mathrm{~cm}^{-1}$ become more intense as the thiram concentration increases. It can also be seen that when the concentration of thiram 
was reduced to $0.024 \mathrm{mg} / \mathrm{L}$, the Raman band remained clearly distinguishable. However, when the concentration of thiram is lower than $0.024 \mathrm{mg} / \mathrm{L}$, the Raman signal cannot be monitored. Therefore, we believe that the limit of detection can reach $0.024 \mathrm{mg} / \mathrm{L}$. In this study, the methyl cellulose film decorated with Ag NPs had more "hot spots" with increasing thiram concentrations, as more Ag NPs were linked with the thiram and then more "hot spots" take effect. Therefore, we believe that the main contribution effect of the SERS substrate was its LSPR effect. Because the Raman peak at $1380 \mathrm{~cm}^{-1}$ was the strongest peak in the SERS spectrum, we used this band to further study the linear function of thiram concentration. The relationship between the SERS intensity at $1380 \mathrm{~cm}^{-1}$ and the thiram concentration is shown in Figure 5B. In the figure, each error bar corresponds to the standard deviation of the SERS intensity collected at five points for each sample. It is observed that the Raman peak intensity of each sample is similar, which indicates the reliability of the MC/Ag NPs film substrate. It can also be seen from Figure 5B that as the logarithm of the thiram concentration increased, the intensity of the Raman spectrum increased non-linearly. When the concentration of thiram was less than $24 \mathrm{mg} / \mathrm{L}$, an excellent linear relationship occurred, and the $\mathrm{R}^{2}$ of the calibration was 0.9979 . When the thiram concentration was higher than $24 \mathrm{mg} / \mathrm{L}$, the intensity of the Raman spectrum increased sharply.
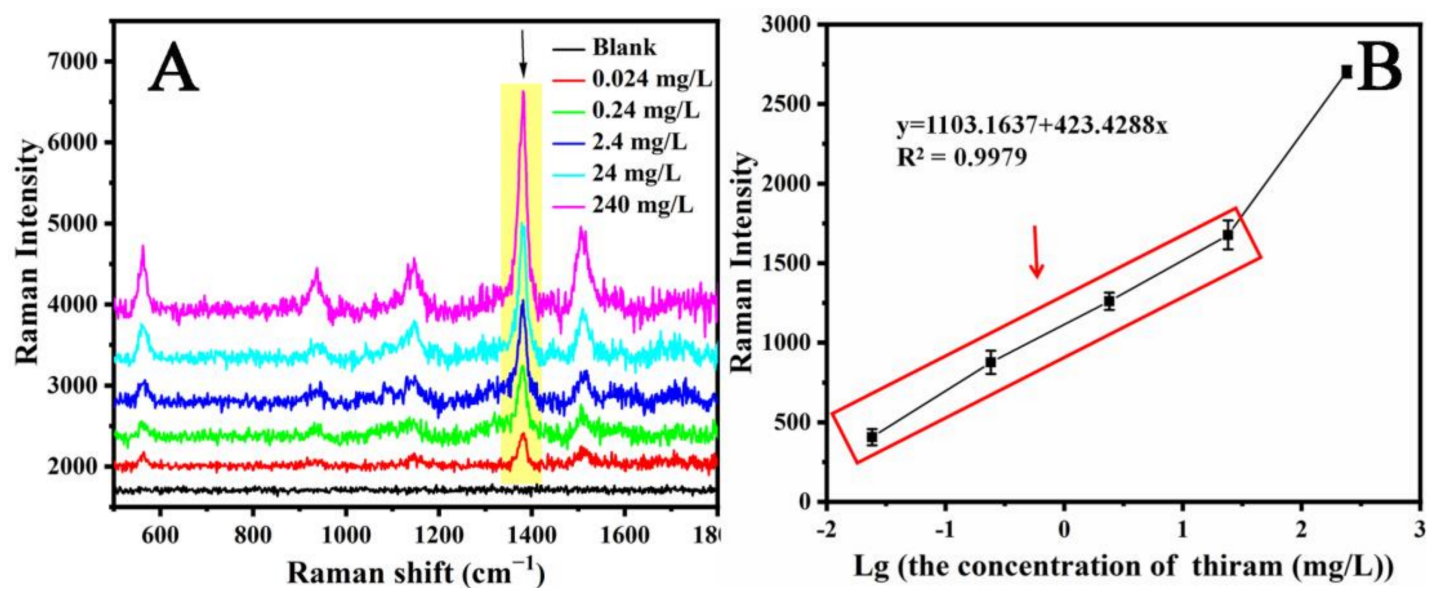

Figure 5. (A) Raman spectra of different concentration of thiram on MC/Ag NPs film substrates. (B) Raman intensity at $1384 \mathrm{~cm}^{-1}$ as a function of thiram concentration with the SERS calibration curve for thiram. Error bars represent the standard deviations of five measurements $(n=5)$.

\subsection{Application in Real Samples}

Thiram is a fungicide used in agriculture to protect food from fungal diseases [35]. To evaluate the practical application of the MC/Ag NPs film, the MC/Ag NPs film substrate was used to detect thiram on various peels. A total of $10 \mu \mathrm{L}$ of thiram was sprayed on $1 \mathrm{~cm} \times 1 \mathrm{~cm}$ squares of tomato and cucumber peels, and then dried in the air. The SERS spectra of the thiram obtained from different peels are shown in Figure 6. The thiram band can be clearly observed at $1380 \mathrm{~cm}^{-1}$, which is the result of $\mathrm{C}-\mathrm{N}$ bond stretching. Obvious characteristic bands can also be observed at 562, 929, 11,466, and $1505 \mathrm{~cm}^{-1}$, which are attributed to $\mathrm{S}-\mathrm{S}$ bond stretching, $\mathrm{C}=\mathrm{S}$ bond stretching or $\mathrm{C}-\mathrm{N}$ bond stretching, $\mathrm{C}-\mathrm{N}$ bond stretching or swing methyl group mode, and $\mathrm{C}-\mathrm{N}$ stretching or deformation of the methyl group [28,36]. It is well known that the surface roughness and chemical composition of the peel are different, so there are some differences in the spectral signal intensity of cucumber and tomato peels. Nevertheless, we can still detect the $2.4 \mathrm{ng} / \mathrm{cm}^{2}$ thiram content on actual samples. The limit of detection was far below the allowable maximum residue limit (MRLs) of thiram in fruits and vegetables set by relevant government agencies [37], indicating that the sensitivity of the MC/Ag NPs film was sufficient to identify thiram residues on the peel. We compare the detection limits of thiram in Table 1 with some reported flexible SERS substrates. The MC/Ag NPs film developed by us achieved good 
results. More importantly, the preparation process of the MC/Ag NPs film was convenient and simple, and did not involve any complex operations or expensive equipment. The $\mathrm{MC} / \mathrm{Ag}$ NPs film is also highly flexible and stable.
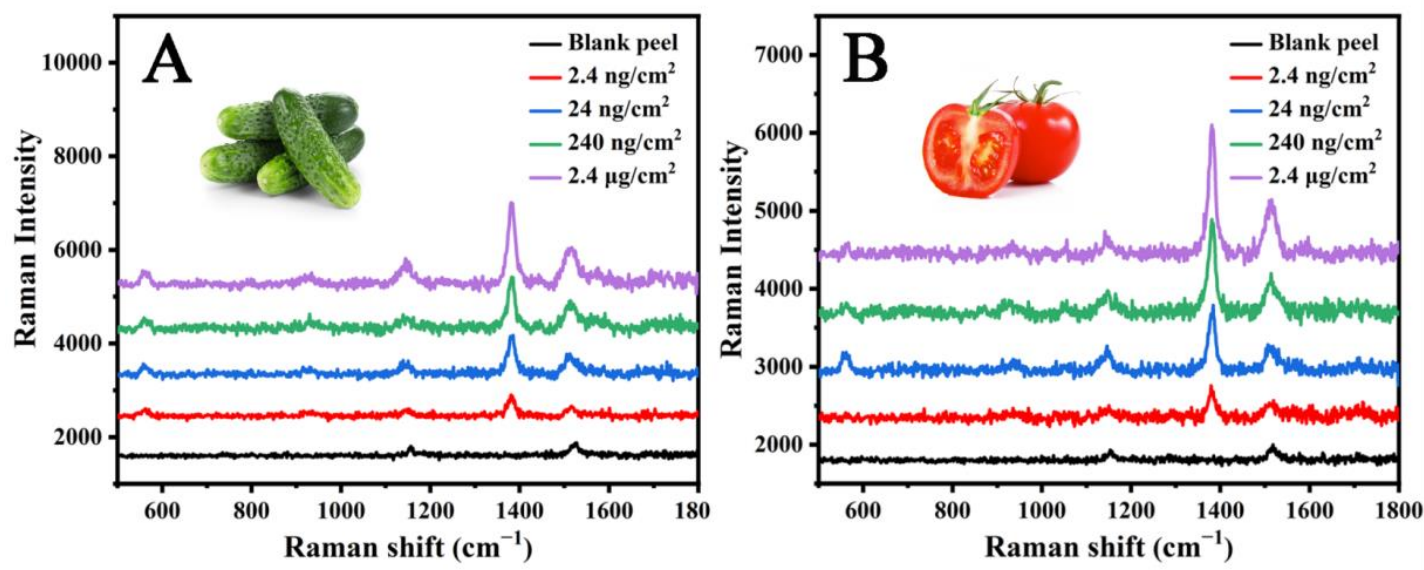

Figure 6. SERS spectra of thiram residues extracted from (A) cucumber peel, and (B) tomato peel using the MC/Ag NPs film substrate.

Table 1. Comparison of the SERS detection performance for thiram using flexible substrates.

\begin{tabular}{cccc}
\hline Substrate & Sample Surface & Detection Limit & Reference \\
\hline AuNPs/tape & Apple & $28.8 \mathrm{ng} / \mathrm{cm}^{2}$ & {$[38]$} \\
$\mathrm{AgNR@Al} \mathrm{O}_{3}$ arrays & Cucumber & $0.24 \mathrm{ng} / \mathrm{cm}^{2}$ & {$[26]$} \\
$\mathrm{AgNRs} / \mathrm{PDMS}$ & Apple & $2.4 \mathrm{ng} / \mathrm{cm}^{2}$ & {$[28]$} \\
& Apple & $4.6 \mathrm{ng} / \mathrm{cm}^{2}$ & \\
$\mathrm{Ag} \mathrm{NPs} /$ filter paper & Pear & $5.2 \mathrm{ng} / \mathrm{cm}^{2}$ & {$[39]$} \\
& Grape & $5.7 \mathrm{ng} / \mathrm{cm}^{2}$ & \\
& Apple & & \\
$\mathrm{T} / \mathrm{Au} @ \mathrm{Ag} /$ PET SERS chip & Tomato & $5 \mathrm{ng} / \mathrm{cm}^{2}$ & {$[40]$} \\
$\mathrm{MC} / \mathrm{Ag}$ NPs film & Cucumber & $0.24 \mathrm{ng} / \mathrm{cm}^{2}$ & This work \\
& Tomato & & \\
\hline
\end{tabular}

\section{Conclusions}

In this study, we demonstrated that methylcellulose decorated with Ag NPs can be used as a new type of flexible SERS substrate. The MC/ Ag NPs film can not only be directly immersed in liquid for SERS detection, but can also be wiped on irregular solid surfaces for SERS detection, thus making it possible to easily sample complex surfaces. The presence of Ag NPs provides rapid and sensitive detection activity for the MC/Ag NPs film substrate. The detection of standard SERS molecules (NBA) revealed the high sensitivity, remarkable reproducibility, and excellent stability of MC/Ag NPs films, which can be produced at low cost. As a practical application, we detected thiram pesticide residues on cucumber and tomato peels. Compared to existing technologies on the market, the proposed MC/Ag NPs film can realize the rapid detection of pesticides without any other treatment. In addition, the MC/Ag NPs film was quite stable when exposed to air and is more convenient to store and transport. Therefore, the use of MC/Ag NPs films to effectively extract targets from complex surfaces supports the use of SERS technology for real-world applications.

Supplementary Materials: The following are available online at https:/ /www.mdpi.com/article/ 10.3390/ma14195750/s1. Figure S1: Contact Angle of MC/Ag NPs film, Figure S2: EDS image of MC/Ag NPs film SERS sute.bstra.

Author Contributions: Conceptualization, L.X. and P.S.; methodology, P.S.; validation, Q.Z. and G.X.; formal analysis, P.S.; investigation, N.G.; resources, L.X. and P.S.; data curation, Q.Z.; writing—original 
draft preparation, Q.Z.; writing-review and editing, T.W.; visualization, P.S.; supervision, P.S.; project administration, L.X., and P.S.; funding acquisition, L.X., and P.S. All authors have read and agreed to the published version of the manuscript.

Funding: This research received no external funding.

Informed Consent Statement: Informed consent was obtained from all subjects involved in the study.

Data Availability Statement: The data presented in this study are available on request from the corresponding author.

Acknowledgments: This work was supported by the National Natural Science Foundation of China (Grant No. 11974152 and 21671089), the LiaoNing Revitalization Talents Program (Grant No. XLYC1807162), the Shenyang High-level Innovative Talents Program (RC200565), the Scientific Research Projects of Liaoning Provincial Department of Education (L2020002), and the Liaoning Provincial Natural Science Foundation Joint Fund Project (2020-YKLH-22).

Conflicts of Interest: The authors declare no conflict of interest.

\section{References}

1. Cereser, C.; Boget, S.; Parvaz, P.; Revol, A. Thiram-induced cytotoxicity is accompanied by a rapid and drastic oxidation of reduced glutathione with consecutive lipid peroxidation and cell death. Toxicology 2021, 163, 153-162. [CrossRef]

2. Chowdhury, M.A.Z.; Jahan, L.; Karim, N.; Alam, M.K.; Rahman, M.A.; Moniruzzaman, M.; Gan, S.H.; Fakhruddin, A.N.M. Determination of carbamate and organophosphorus pesticides in vegetable samples and the efficiency of gamma-radiation in their removal. Biomed. Res. Int. 2014, 2014, 145159. [CrossRef] [PubMed]

3. Golge, O.; Cinpolat, S.; Kabak, B. Quantification of pesticide residues in gherkins by liquid and gas chromatography coupled to tandem mass spectrometry. J. Food. Compos. Anal. 2021, 96, 1003755. [CrossRef]

4. Debayle, D.; Dessalces, G.; Grenier-Loustalot, M.F. Multi-residue analysis of traces of pesticides and antibiotics in honey by HPLC-MS-MS. Anal. Bioanal. Chem. 2008, 391, 1011-1020. [CrossRef] [PubMed]

5. $\quad$ Langer, J.; de Aberasturi, D.J.; Aizpurua, J.; Alvarez-Puebla, R.A.; Auguié, R.A.; Baumberg, J.J.; Bazan, G.C.; Bell, S.E.; Boisen, A.; Brolo, A.G. Present and future of surface-enhanced Raman scattering. ACS Nano 2020, 14, 28-117. [CrossRef] [PubMed]

6. Zhou, X.; Pu, H.; Sun, D.W. DNA functionalized metal and metal oxide nanoparticles: Principles and recent advances in food safety detection. Crit. Rev. Food Sci. Nutr. 2020, 61, 2277-2296. [CrossRef]

7. Wang, K.; Sun, D.W.; Pu, H.; Wei, Q. Surface-enhanced Raman scattering of core-shell Au@Ag nanoparticles aggregates for rapid detection of difenoconazole in grapes. Talanta 2019, 191, 449-456. [CrossRef]

8. Li, J.; Wang, W.; Zhang, H.; Lu, Z.; Wu, W.; Shu, M.; Han, H. Programmable DNA tweezer-actuated SERS probe for the sensitive detection of AFB1. Anal. Chem. 2020, 92, 4900-4907. [CrossRef]

9. He, H.; Sun, D.W.; Pu, H.; Chen, L.; Lin, L. Applications of Raman spectroscopic techniques for quality and safety evaluation of milk: A review of recent developments. Crit. Rev. Food Sci. Nutr. 2019, 59, 770-793. [CrossRef]

10. Hussain, A.; Sun, D.W.; Pu, H. Bimetallic core shelled nanoparticles (Au@AgNPs) for rapid detection of thiram and dicyandiamide contaminants in liquid milk using SERS. Food Chem. 2020, 317, 126429. [CrossRef] [PubMed]

11. Sarfo, D.K.; Izake, E.L.; O'Mullane, A.P.; Ayoko, G.A. Fabrication of nanostructured SERS substrates on conductive solid platforms for environmental application. Crit. Rev. Environ. Sci. Technol. 2019, 49, 1294-1329. [CrossRef]

12. Samanta, A.; Maiti, K.K.; Soh, K.S.; Liao, X.; Vendrell, M.; Dinish, U.; Yun, S.W.; Bhuvaneswari, R.; Kim, H.; Rautela, S. Ultrasensitive near-infrared Raman reporters for SERS-based in vivo cancer detection. Angew. Chem. Int. 2011, 50, 6089-6092. [CrossRef] [PubMed]

13. Managò, S.; Zito, G.; Rogato, A.; Casalino, M.; Esposito, E.; De Luca, A.C.E. Bioderived three-dimensional hierarchical nanostructures as efficient surface-enhanced Raman scattering substrates for cell membrane probing. ACS Appl. Mater. Interfaces 2018, 10, 12406-12416. [CrossRef] [PubMed]

14. Zhu, D.; Li, Z.; Sun, D.W. Visualization of the in situ distribution of contents and hydrogen bonding states of cellular level water in apple tissues by confocal Raman microscopy. Analyst 2020, 145, 897-907.

15. Roh, J.Y.; Matecki, M.K.; Svoboda, S.A.; Wustholz, K.L. Identifying pigment mixtures in art using SERS: A treatment flowchart approach. Anal. Chem. 2016, 88, 2028-2032. [CrossRef]

16. Wu, L.; Pu, H.; Huang, L.; Sun, D.W. Plasmonic nanoparticles on metal-organic framework: A versatile SERS platform for adsorptive detection of new coccine and orange II dyes in food. Food Chem. 2020, 328, 127105. [CrossRef]

17. Hu, B.; Sun, D.W.; Pu, H.; Wei, Q. A dynamically optical and highly stable pNIPAM@Au NRs nanohybrid substrate for sensitive SERS detection of malachite green in fish fillet. Talanta 2020, 218, 121188. [CrossRef]

18. Jiang, Y.; Sun, D.W.; Pu, H.; Wei, Q. Ultrasensitive analysis of kanamycin residue in milk by SERS-based aptasensor. Talanta 2019, 197, 151-158. [CrossRef]

19. He, H.; Sun, D.W.; Pu, H.; Huang, L. Bridging Fe3O4@ Au nanoflowers and Au@ Ag nanospheres with aptamer for ultrasensitive SERS detection of aflatoxin B1. Food Chem. 2020, 332, 127443. [CrossRef] 
20. Hussain, N.; Pu, H.; Hussain, A.; Sun, D.W. Rapid detection of ziram residues in apple and pear fruits by SERS based on octanethiol functionalized bimetallic core-shell nanoparticles. Spectrochim. Acta A 2020, 236, 118357. [CrossRef]

21. Yaseen, T.; Pu, H.; Sun, D.W. Fabrication of silver-coated gold nanoparticles to simultaneously detect multi-class insecticide residues in peach with SERS technique. Talanta 2019, 196, 537-545. [CrossRef]

22. Lin, X.M.; Cui, Y.; Xu, Y.H.; Ren, B.; Tian, Z.Q. Surface-enhanced Raman spectroscopy: Substrate-related issues. Anal. Bioanal. Chem. 2009, 394, 1729-1745. [CrossRef]

23. Ma, Y.; Du, Y.; Chen, Y.; Gu, C.; Jiang, T.; Wei, G.; Zhou, J. Intrinsic Raman signal of polymer matrix induced quantitative multiphase SERS analysis based on stretched PDMS film with anchored Ag nanoparticles/Au nanowires. Chem. Eng. J. 2020, 381, 122710. [CrossRef]

24. Wang, K.; Sun, D.W.; Pu, H.; Wei, Q.; Huang, L. Stable, flexible, and high performance SERS chip enabled by a ternary film-packaged plasmonic nanoparticle array. ACS Appl. Mater. Interfaces 2019, 11, 29177-29186. [CrossRef] [PubMed]

25. Wang, C.; Wong, K.W.; Wang, Q.; Zhou, Y.F.; Tang, C.Y.; Fan, M.K.; Mei, J.; Lau, W.M. Silver-nanoparticles-loaded chitosan foam as a flexible SERS substrate for active collecting analytes from both solid surface and solution. Talanta 2019, 191, 241-247. [CrossRef] [PubMed]

26. Chen, J.; Huang, Y.J.; Kannan, P.; Zhang, L.; Lin, Z.Y.; Zhang, J.W.; Chen, T.; Guo, L.H. Flexible and adhesive surface enhance Raman scattering active tape for rapid detection of pesticide residues in fruits and vegetables. Anal. Chem. 2016, 88, 2149-2155. [CrossRef]

27. Huo, D.X.; Chen, B.; Meng, G.W.; Huang, Z.L.; Li, M.T.; Lei, Y. Ag-Nanoparticles@Bacterial Nanocellulose as a 3D flexible and robust Surface-Enhanced Raman Scattering substrate. ACS Appl. Mater. Interfaces 2020, 45, 50713-50720. [CrossRef]

28. Kumar, S.; Goel, P.; Singh, J.P. Flexible and robust SERS active substrates for conformal rapid detection of pesticide residues from fruits. Sens. Actuators B Chem. 2017, 241, 577-583. [CrossRef]

29. Desmonda, C.; Kar, S.; Tai, Y. Formation of gold nanostructures on copier paper surface for cost effective SERS active substrateEffect of halide additives. Appl. Surf. Sci. 2016, 367, 362-369. [CrossRef]

30. Arvanitoyannis, I.; Biliaderis, C.G. Physical properties of polyol-plasticized edible blends made of methyl cellulose and soluble starch. Carbohydr. Polym. 1999, 38, 47-58. [CrossRef]

31. Cai, W.B.; Ren, B.; Li, X.Q.; She, C.X.; Liu, F.M.; Cai, X.W.; Tian, Z.Q. Investigation of surface-enhanced Raman scattering from platinum electrodes using a confocal Raman microscope: Dependence of surface roughening pretreatment. Surf. Sci. 1998, 406, 9-22. [CrossRef]

32. Álvarez-Puebla, R.A. Effects of the Excitation Wavelength on the SERS Spectrum. J. Phys. Chem. Lett. 2012, 3, 857-866. [CrossRef]

33. Chen, J.; Wang, X.X.; Tang, F.; Ye, X.; Yang, L.M.; Zhang, Y.B. Substrates for surface-enhanced Raman spectroscopy based on TiN plasmonic antennas and waveguide platforms. Results Phys. 2020, 16, 102867. [CrossRef]

34. Wang, K.Q.; Sun, D.W.; Pu, H.B.; Wei, Q.Y. Two-dimensional Au@Ag nanodot array for sensing dual-fungicides in fruit juices with surface-enhanced Raman spectroscopy technique. Food Chem. 2020, 310, 125923. [CrossRef]

35. Hu, B.; Sun, D.W.; Pu, H.; Wei, Q. Rapid nondestructive detection of mixed pesticides residues on fruit surface using SERS combined with self-modeling mixture analysis method. Talanta 2020, 217, 120998. [CrossRef] [PubMed]

36. Sanchez-Cortes, S.; Vasina, M.; Francioso, O.; Garcia-Ramos, J. Raman and surface-enhanced Raman spectroscopy of dithiocarbamate fungicides. Vib. Spectrosc. 1998, 17, 133-144. [CrossRef]

37. Anonymous. National Food Safety Standard-Maximum Residue Limits for Pesticides in Food; Chinese National Standard GB: Hangzhou, China, 2016.

38. Jiang, J.; Zou, S.; Ma, L.; Wang, S.; Liao, J.; Zhang, Z. Surface-enhanced Raman scattering detection of pesticide residues using transparent adhesive tapes and coated silver nanorods. ACS Appl. Mater. Inter. 2018, 10, 9129-9135. [CrossRef] [PubMed]

39. Wang, K.; Huang, M.; Chen, J.; Lin, L.; Kong, L.; Liu, X.; Wang, H.; Lin, M. A “drop-wipe-test” SERS method for rapid detection of pesticide residues in fruits. J. Raman Spectrosc. 2018, 49, 493-498. [CrossRef]

40. Wang, K.Q.; Sun, D.W.; Pu, H.B.; Wei, Q.Y. Polymer multilayers enabled stable and flexible Au@Ag nanoparticle array for nondestructive SERS detection of pesticide residues. Talanta 2021, 223, 121782. [CrossRef] [PubMed] 